\title{
Simulation of tetraetherlipids on solid surfaces - an extension of the DPD-model
}

\section{Christoph Engels*, H Kuhn and D Richter}

Address: CAM-D Technologies GmbH, Gerlingstr. 65, D-45139 Essen, Germany

* Corresponding author

from 3rd German Conference on Chemoinformatics

Goslar, Germany. II-I3 November 2007

Published: 26 March 2008

Chemistry Central Journal 2008, 2(Suppl I):P33 doi:I0.II86/I752-I53X-2-SI-P33

This abstract is available from: http://www.journal.chemistrycentral.com/content/2/SI/P33

(c) 2008 Engels et al.

Glyceroldialkylnomizoltetraetherlipid (GDNT) is a tetraetherlipid that can be extracted from archaebacteria and that is known for its antifouling capabilities [1]. Therefore it is of interest to find out whether solid surfaces can be coated with this material in order to generate resistant devices for water analytics.

Recently we developed a new mesoscopic molecular modelling computer simulation method from the Dissipative Particle Dynamics (DPD) method [2] useful for simulations of specific dynamical processes at the microsecond and micrometer scale. This unique technique, called Molecular-Fragment-Dynamics (MFD), can be generally applied to surfactants, polymers, nanoparticles and complex mixtures in materials and life science simulation studies [3]. In MFD the molecule is divided into different regions of molecular fragments. Therefore, the MFD scheme overcomes the limitations of classic atomic scale simulations.

This method has been applied to a system of GDNT in three different solvents (e.g. cyclohexane, chloroform and carbon tetrachlorine) at the interface with a solid borofloate substrate. Goal of the study was to find out at which concentration of GDNT and in which solvent the best levels of aggregation could be reached and how such coated surfaces look like. The results of the study will be presented on the poster with pictures and graphs.

\section{References}

I. Patent PCT WO 2006/002616 AI. 2006.
2. Jensen F: Introduction to Computational Chemistry. John Wiley \& Sons, New York; 2006.

3. Ryjkina E, et al.: Angew Chem Int Ed 2002, 4 I (6):983. 